\title{
Analysis of the Optimization Path of Architectural Design Based on Traditional Folk Culture
}

\author{
Aifeng Wang ${ }^{1}$, Bei Wang ${ }^{2,}$ \\ ${ }^{1}$ Nanyang Institute of Technology, Nanyang City, Henan Province, 473004, China \\ ${ }^{2}$ Zhengzhou Foreign Language School, Zhengzhou City, Henan Province, 450000, China
}

Keywords: Traditional folk house culture; Architectural design; Optimization path; Inheritance and development

\begin{abstract}
The deep research of traditional residence and its culture not only lies in the systematic induction and summary of traditional architecture, but also more importantly, it absorbs the essence of traditional architecture and makes the traditional elements apply and serve the modern architectural design. Based on the author's learning and practical experience, this paper firstly analyzed the spatial organization and cultural elements of Chinese traditional dwellings, and then explored the optimal path of modern architectural design. This article studied the inheritance and development of traditional folk house culture in modern architecture, which helps to combine traditional context with contemporary architecture.
\end{abstract}

\section{Introduction}

With the development of society and the progress of the times, traditional dwellings are becoming the good materials for various studies with their strong ecological spirit, regional, cultural, historic and national characteristics. At present, the characteristic expression of various buildings is not clear. Time and historical intercourse collide with each other. In the unity of opposites, we constantly seek new and different visual beauty. Architecture culture is not closed, but it is the product of inheritance, creation and continuity. The traditional transformation should be used for reference in innovation. We can draw on the features, forms and language of historical buildings through accurate methods. We should deeply understand the essence of traditional residential architecture, and understand its development context, starting from the whole and details. We should also refine the essence of traditional residential architecture for the design of modern residential buildings, inherit the history, dare to innovate, and strive to realize the modern residential design with the characteristics of the times.

\section{The Spatial Organization and Cultural Elements of Chinese Traditional Dwellings}

Folk house is a rich cultural form, reflecting the local residents' traditional culture and customs and integrating them into the local natural ecological environment. It can be seen that the local characteristics of residential areas are deeply reflected in the space organization and its components. In addition, Taoism advocates the concept of closing to nature and individuality, which has far-reaching influence on residential culture. To this end, China's traditional residential buildings often advocate a simple, restrained and humanized living mode. Chinese folk houses have strong local flavor, and they express the love for their hometown and the feeling of nature. Chinese houses and life, ethnic customs and pleasant space scale moving, are the combination of rational and romantic, which often endowed with a situation of "feeling and setting are happily blended". The formation of dwellings is related to society, culture and customs, as well as climate, geography and other natural conditions. This makes the layout, structure, appearance and internal and external space of the residence different from each other. This difference determines the local features of the vernacular dwellings. For example, the ancient residence of Xi'an is commonly called Xi'an 
courtyard, but it is different from the courtyard of Beijing. Beijing's courtyard is a single family courtyard, and there is no distinction between front and rear courtyard. Xi'an quadrangles generally have two to three, rectangular, it is typically "big"; in addition, the ancient dwellings in Xi'an, except for a small number of Ming Dynasty folk houses, were mainly built during the Qing Dynasty and the Republic of china. In the past, most of the buildings are houses of the merchant or officials, and most of them have the exquisite carvings with very high artistic value. The ancient houses in Xi'an not only carry forward the understanding and thinking of architecture, astronomy, philosophy, human relations, politics and so on, but also record the wisdom of Chinese existence, thus it accumulates into the organic parts of the ancient city's traditional culture.

\section{The Optimization Path of Modern Architectural Design Based on Traditional Folk Culture}

Pay attention to the inheritance and integration of the traditional folk house culture from macroscopical view. The first is to find the traditional context, and inherit the regional Charm. To inherit the style and style of traditional residential buildings, we should firstly have a comprehensive understanding of the historical traditions, geographical features and traditional architectural forms of Guanzhong. Under such premise, we sum it up to the architectural creation, and understand its features and modeling charms. We integrate modern and practical functional requirements into the modern architecture form with traditional patterns and features. The second is using building materials to shape new buildings. As for the best way to reflect the regional context of architecture and the clues of the times, the use of building materials collocation becomes the most important. Although the raw materials of local ecology can reflect the traditional texture and context, we must comply with the requirements of various aspects under the influence of modernism. Under the condition of using some new ecological materials, we use traditional materials to match it, so that it becomes the highlight of new wind architecture. As a result, the new architecture can preserve the traditional context and shape and texture, and the traditional construction techniques and materials are carefully grafted together with modern construction techniques. Taking the traditional residential buildings in Guanzhong area as an example, the building materials should conform to the local traditional culture in terms of color and material. Color: the traditional residential buildings in Guanzhong area are more restrained in appearance and color, and the colors are more plain. There is no superfluous decorative color. The traditional residential buildings in Guanzhong area are mainly made up of grey, white, yellow and other colors. The elegant color gives a deep, peaceful feeling, and reflects a strong cultural background. As shown in Figure 1, the project in the construction of color control always adhere to the principle of "abandoning Yan, seeking vegetarian" followed the Guanzhong traditional architectural colors. It uses grey roof, brick walls with a large area of white wall. At the same time, it also provides a good background collocation for all kinds of plants and stone carvings in the area.

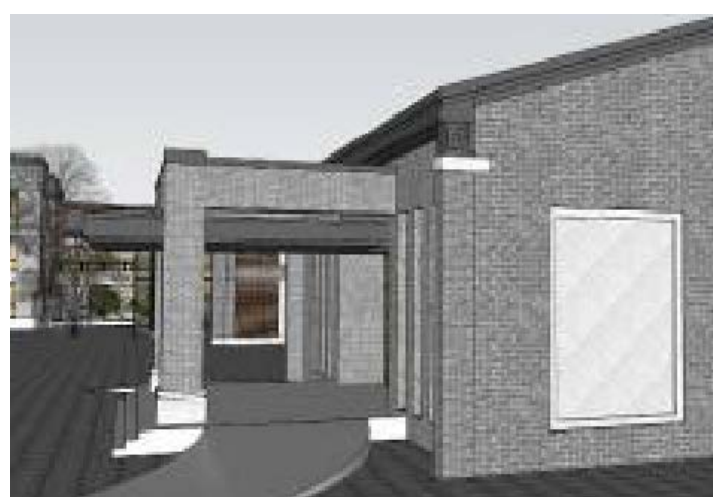

Fig.1 the new style of Architecture under a reasonable mix of colors

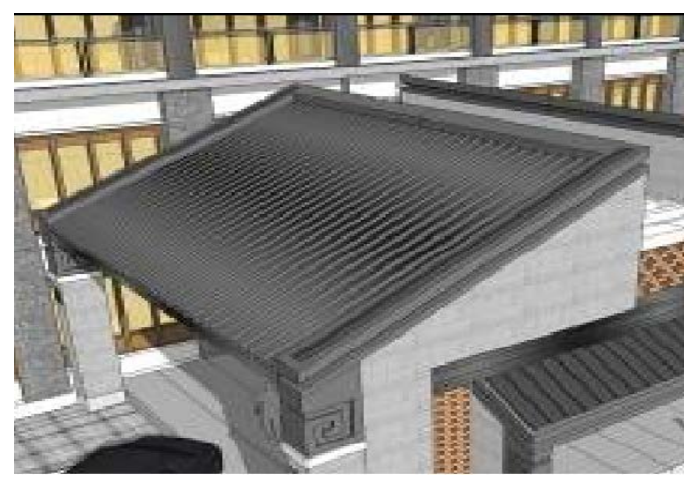

Fig.2 the new style architecture style under a reasonable mix of materials

Material: traditional buildings are affected by local environmental factors, and it uses blue-stone, lesso and wood as building materials. The options choose brick, gray steel, a large area of white 
walls and wooden grid as the main building materials from VIP guest rooms to hotel dining rooms, lobby, and front door building materials. As shown in Figure 2, the roof adopts the methods of black steel tile and blankholding processing, so that to form an organization of high and low dimensions, which enrich the joint sense of roof image and block. Walls are made of brick and lime decoration, forming fenqiangdaiwa architectural image. Granite is used for floor paving in the hotel area. We use modern technological techniques to imitate traditional art forms. It can be said that the design of the building materials for the entire architectural community has both a modern flavor and a unified tradition of regional architectural features. Among them, there is also no lack of the use of modern emerging technology materials to increase people's comfort level.

Pay attention to the embodiment of traditional folk house elements from micro view. Traditional residential buildings can not meet the needs of the modern life of the residents in the aspects of construction materials, construction technology, space layout and so on. For example, traditional houses made of bamboo, wood, green, natural materials, are not suitable for large-scale and mechanical structure of the modern residential construction; thus, in architectural design, the problem like how to utilize modern design technology to introduce the traditional ethnic and geographical characteristics into modern city residential and fully demonstrate the geographical features of traditional residence in northern Guangxi if residential design meets the needs of the residents of the modern life at the same time is an important task for many architects. The elements of traditional dwellings suitable for modern residential buildings are mainly shown as follows:

First, planning and site selection should in accordance with local conditions. The location of traditional residential settlement reflects the view of Taoism: "no man helps the sky" and "no man to destroy the sky", which emphasizes the harmony between man and nature, and the harmony between architecture and environment, and the realm of natural and true interest. Secondly, in the layout of the architecture and its space combination, the layout of the traditional residential buildings is flexible. The traditional residential settlement conforms to the geographical condition layout pattern and the space combination, and it not only saves the land effectively, but also preserves the natural original appearance to the greatest extent, which embodies the ideal of symbiosis between architecture and nature. Therefore, on the one hand, it can enrich the appearance of the region and improve the overall beauty of the city and the facade effect of the block; on the other hand, it makes the house itself more perfect. Therefore, the traditional residential planning and site selection according to local conditions has brought us enlightenment. In the planning, it can form a good design basis combined with the residential background and its own characteristics. We should not only consider the correlation of the background environment, but also actively explore the content of new space, so that to increase the attractiveness of the city.

Second, in dynamic contact spaces, communication between modern city dwellers is rare, and even neighbors are strangers. Traditional Chinese saying says that "distant relatives are not as close neighbors", so neighbors are an important part of life. Being in harmony with your neighbors strengthens your sense of belonging and security. You can also enjoy fun and strengthen your emotions in communication.

Thirdly, creation of landscape and artistic conception with beautiful architectural art are endowed with pleasant value. Residential landscape has two levels of role: one is the harmony and innovation of the residential regional landscape, that is, as an element of the city, the residential areas contribute to the urban landscape; on the other hand, it creates the whole landscape of the residential area, that is, the interior landscape organization and its aesthetic make contribution to the residents.

\section{Summary}

The folk house culture is extensive and profound. While strengthening the protection of traditional dwellings, good design can be refined from traditional vernacular architecture language. We make good use of it to the modern city residential design, which not only protect and inherit the traditional architectural culture of the local, but also enrich the modern architecture of the national and regional characteristics. This is also of great significance to the creation of a city's image. 


\section{Acknowledgements}

Fund project: Key scientific and technological project of Henan Province in 2015: A study on spatial optimization strategy of immigrant new village - Taking Nanyang city as an example. (152102310026)

\section{References}

[1] Li Qin. On the Design Methods of Traditional Dwellings[J]. Building Materials and Decoration, 2016, (17): 159-160.

[2] Ma Xuan, Ma Yuwei. Analysis of Decorative Arts of Traditional Residential Buildings in Xuzhou[J]. Journal of Jiangsu Architecture, Career Technical College, 2015, (04): 49-52.

[3] Jiguang Qiu, Zhou Sisi. Application Experience of Ecological Experience in Architectural Design[J]. The Chinese Residential (Late Month), 2014 (04): 57-58.

[4] Liu Suwen, Li Xianfeng, Guo Yongpei. Study on Cultural Values of Courtyard Buildings in Chinese Traditional Dwellings[J]. Journal of Changzhou University (Social Science Edition), 2013, (06): 25-28.

[5] Tao Yuan, sun, Yang Xu, Tang Xiaoxiang. Inheritance and Innovation of Traditional Residential Architectural Culture -- A Summary of the Nineteenth Academic Conference on Chinese Residential Architecture[J]. South Architecture, 2012, (06): 6-7.

[6] Fan Hongwu. Characteristics and Inspiration of Architectural Design of Modern Suzhou Folk House[J]. Art Hundred, 2012, (S2): 168-169+180.

[7], Li Xueping. The Ecological Culture of Chinese Traditional Residential Buildings[J]. Anhui Agricultural Science, 2010, (13): 7070-7071+7167. 